\title{
Success despite the Silos: System-Wide Innovation and Collaboration
}

\author{
Elizabeth K. Briody \\ Cultural Keys LLC \\ Ken C. Erickson \\ University of South Carolina and \\ Pacific Ethnography Company
}

\begin{abstract}
A review of the literature on silos in organizations reveals that they are a metaphor to signal dysfunction and difficulty. To explore the range of factors that come into play when projects in an organization demand interaction and support across silos, we present examples from three organizations: an intimate apparel company, a global automotive firm, and a hospital. We find similar problems and patterns within this ethnographic exploration of silos, different innovation pathways, and different results that are useful in understanding how silos work and how they are overcome as organizations respond to changing external conditions.
\end{abstract}

\section{INTRODUCTION}

People who work in large organizations often lament the decentralized structures that define their work functions and day-to-day activities. Finance, IT, supply chain, legal, and any number of other organizational functions exhibit cultures that are distinctive in their work practices, processes, and perspectives. Colloquially referred to as "silos," these internal organizational units are often characterized as impenetrable and are frequently the subject of finger pointing and blame. They seem to stand in opposition to each other; the people within them seem to be optimizing for their own individual area rather than for the wellbeing of the wider corporate whole.

Yet, collaboration is typically expected across silos since multiple functional areas must contribute to getting the work of the organization done. We define collaboration as "working in concert with others in the pursuit of particular goals" (Briody, Trotter, Meerwarth, 2010, p.7). Moreover, system or organizationwide innovation is often necessary to enable organizations to respond to environmental pressures and market challenges, improve their products and services over time, and address internal organizational issues. We use Rogers (2003, p.12) definition of innovation: "an idea, practice, or object that is perceived as new by an individual or other unit of adoption." We focus primarily on ethnographic contexts in which we saw innovation attempted. For us, system-wide innovation implies penetration of the innovation across the entire system such that the organizational structure and dynamics support the innovation. Given the tendency to align within silos as part of an organizational function, and the overarching organizational goal to develop and deliver products and services (sometimes requiring innovation) across silos, organizational members typically find themselves embroiled in internal contradictions and conflict. We argue that understanding the interplay between silo-ed organizational structure and collaboration offers 
clues to innovation success. Indeed, the presence of specific organizational-culture characteristics, including collaboration, is responsible for the realization of system-wide innovation.

\section{LITERATURE FOCUS}

Scholars have used the term silo to refer to the "horizontal axis" or areas of specialization within a hierarchical organization (Diamond, Stein, and Allcorn, 2002, p.280). Such divisions are characterized by a single function, product, or area of focus just as cylindrical storage containers on farms are used for storing a single type of food for livestock (Vermeulen, Puranam, and Gulati, 2010, p.72; Neebe, 1987, p.815). Applying this farm metaphor to business organizations enables understanding of how large organizations are structured and differentiated based on areas of expertise, training, and day-to-day work activities. Indeed, organizations purposely cluster specialized knowledge and competencies together to gain depth as well as economies of scale (Gulati, 2007, p.2). Silos create "efficient structures for executing strategy" (Kleinbaum, Stuart, and Tushman 2008, p.1). Moreover, the boundaries between silos can be both "productive and anxiety reducing" since the "purpose, responsibility, and authority and coordination of work" within them are well defined (Diamond, Stein, and Allcorn, 2002, p.293).

\section{Silos as a Metaphor for Dysfunction}

Yet, the silo metaphor is typically employed to signal difficulties in organizational functioning. For instance, Lencioni (2006, p.175) points out that

Silos are nothing more than the barriers that exist between departments within an organization, causing people who are supposed to be on the same team to work against one another. And whether we call this phenomenon departmental politics, divisional rivalry, or turf warfare, it is one of the most frustrating aspects of life in any sizeable organization.

Similarly, Diamond, Allcorn, and Stein (2004, p.46) indicate that an "'us versus them' mindset" and "inter-silo cultural chauvinism" appear in the internal, every-day discourse about other parts of the organization. The term silo has been used to describe organizations and their management teams "that lack the desire or motivation to coordinate (at worst, even communicate) with other entities in the same organization...High costs are borne from duplication of effort, inconsistencies, and inefficiencies" (Serrat, 2010, p.1-2). As an example, Intensive Care Units have been portrayed as a "parallel, but minimally interactive work environment" since both physicians and nurses "interact only briefly during rounds and at the bedside of unstable patients" (Curtis and Shannon, 2006, p.16). Cilliers and Greyvenstein (2012, p.3-4) summarize much of the literature, emphasizing both the "silo as invisible barrier" and the "silo as container," and conclude $(2012$, p.8) that the "silo mentality" is tied to "destructive differentiation and breaking down of connection."

\section{Collaboration as Goal and Remedy}

The scholarly literature on silos, which spans business types ranging from manufacturing (Aaker, 2013) through public administration (Bundred, 2006), points to many tactical remedies to the problems that arise from organizational silos. These prescriptions include structural changes to the organization (Cash, Earl, and Morison, 2008; Vermeulen, Puranam and Gulati, 2010), spatial rearrangements to encourage interaction (Thomas and Hern, 2006), and reorganized IT efforts (Bannister, 2001), among others. All these solutions aim for the same result. They point to a general consensus in the literature that collaboration and communication are both the process for and the solution to the issues experienced by silo-ed organizations. "In most situations, silos rise up not because of what executives are doing purposefully but rather because of what they are failing to do: provide themselves and their employees with a compelling context for working together" (Lencioni 2006, p.175). Collaboration and cooperation are said to become "trapped" within the silos whether those units are based on function, product, geography, or market (Vermeulen, Puranam, and Gulati 2010, p.72). Therefore, Vermeulen and colleagues propose an organizational shake-up based on the results of a "corporate cholesterol test" or questionnaire 
to corporate managers. If employee interaction is limited largely to within-group contact, communication breakdowns occur along silo boundaries, well-established routines are not questioned, and influential groups and individuals command most of the firm's resources, then some cross-silo restructuring is needed.

\section{Strategies to Foster Collaboration}

Researchers from a wide array of disciplines (e.g., health care, business, human-computer interaction, library science) have proposed ways to improve organizational functioning in silo-ed structures through collaborative approaches. Interprofessional education is one step in raising awareness of the broader work context, and in acquainting young professionals with team-based approaches to work (Bandali et al., 2011; Miller et al., 2010; Margarlit et al., 2009; Herbert, 2005). Shirey (2006) argues that "intrapreneurs" or organizational change agents such as clinical nurse specialists can help break down professional silos. However, others suggest that the interdisciplinary activity is "far too low" in numbers (Newhouse and Spring, 2010, p.312) - particularly within academic and clinical settings - and that a paradigm shift needs to occur in which groups rather than individuals are rewarded. In business organizations defined by sharply silo-ed structures, collaboration is not rewarded - whether internally among employees of different silos, or externally with customers, suppliers, and partners (Gulati, 2007). Incentives are an important catalyst for collaboration to thrive as reported in endeavors involving libraries, archives, and museums, though other catalysts may be necessary as well including a vision, a mandate, resources, and trust (Zorich et al., 2008), or direct involvement in the initiative such as from a user community (Foster, 2013).

\section{Collaboration, Organizational Innovation, and Transformation}

Many scholars have outlined processes or frameworks for encouraging collaboration, and through that collaboration, the successful implementation of organizational innovations or change. Discussing American organizations in general, Diamond, Stein, and Allcorn (2002, p.294-5) suggest involving both management and employees in a "shared process" of planning and implementing organizational change. Organizational learning and problem solving become the focal points, rather than the "defensive routines of the silo mentality (2002, p.286)." Lencioni (2006) offers a four-part model for addressing silo problems and achieving organizational goals:

1. Developing a thematic goal, a top priority, that is time limited (i.e., between 6-12 months) and shared by the entire organization (e.g., rebuild our credibility in the market)

2. Defining objectives that are the building blocks of the thematic goal (e.g., establish a comprehensive strategy, create a unified marketing message)

3. Including standard operating objectives - the ongoing organizational priorities (e.g., market share by product category, customer satisfaction)

4. Metrics or ways with which to measure progress.

Simplifying and measuring the organization's work in this way breaks down the silos and aligns organizational members toward the future. In perhaps one of the most well-known silo-ed corporations in the world, Briody, Trotter, and Meerwarth (2010) document the decentralized structure and autonomous culture of General Motors (GM) and propose models to create an ideal culture based on collaboration and processes and tools to achieve that ideal.

Less well depicted in the literature is whether, and under what conditions, collaboration emerges in the process of innovating in a silo-ed organizational structure. In the event that collaboration takes hold, it does so within a broader, dynamic cultural context. Neither the desire to collaborate (Briody, Trotter, and Meerwarth, 2010), nor the prescription to collaborate (c.f., Lencioni, 2006) offer insights into what actually happens when collaboration is attempted. Important insights about silo bridging are beginning to emerge from quantitative social network analysis of electronic communication in organizations. Recent work there reports that "although theories of communication and coordination are central ... we have theories and assumptions but little empirical evidence about the structure of communication in the modern, complex organization" (Kleinbaum, Stuart, and Tushman, 2008 p.45). Thus, there is little 
descriptive, in-context detail on the day-to-day culture of the silos in relation to other silos or the sequence of actions as the innovation progresses through the organization.

The same might be said of much of the research on innovation in business, which often uses largescale, experience-distant data sets to explore hypotheses about the effects of cross-company collaboration, the effects of industrial clustering, or the effects of organizational culture on innovation. Such studies often depict innovation as the dependent variable that is operationalized using measures such as patent applications or manager responses to surveys about innovation. On the one hand, reductive proxy measures are useful for comparative work and hypothesis testing. On the other hand, they oversimplify the many ways in which innovation, however defined, actually happens in organizational practice. From an anthropological point of view, the notion of innovation seems under-theorized. Ethnographers' concern with "counting to one" (Kirk and Miller 1986, p.9), that is, identifying which characteristics or influencers contribute to any given issue, has not yet been clearly addressed.

Only rarely have observation methodologies been employed which would enable researchers to access the activity level theories-in-use enacted in the workplace. Yet, it is at this 'micro level' that the managerial reality enfolds every day, therefore a theory of innovation needs to connect the action (praxis) with the managerial and academic theories (practice) by understanding the role of agents (practitioners) (Crossan and Apaydin, 2010 p.1178-1179).

In this article, we present examples of organizational practice and praxis in three organizations in which formally-designated and informally-driven leaders recognize the importance of external environmental changes, respond to them with organizational process or product innovations, and experience varying degrees of innovation success. In the examples involving an intimate apparel company, only halting efforts at cross-silo collaboration were evident. In the GM example involving one of its first global vehicle programs, there was an attempt at mandated cross-silo collaboration but without changing any of the relevant structural mechanisms to support it. In the examples associated with a large hospital, cross-silo collaboration was sometimes helpful for innovation success and sometimes not. We focus our attention on the following questions:

- What accounts for these different organizational experiences related to system-wide innovation?

- What role does collaboration play in system-wide innovation?

- What cultural responses are activated within and across silos during innovation?

Studies of innovation as process are "underdeveloped in the literature" (Crossan and Apaydin, 2010 p.1167). The ethnographic vantage point we offer not only is a step toward crafting ethnographic accounts of innovation in the everyday context of organizational culture, but it also addresses the problem of silos. We believe this approach is a useful, relevant, and timely contribution to innovation research as well as to those organizational leaders trying to innovate.

\section{DATA AND METHODS}

Three different ethnographic research projects on which we worked either individually or as members of larger research teams form the basis of our analysis. The projects were unrelated to each other and had their own research goals. We brought the three projects together to write this article. Articles and chapters have been published about aspects of the global vehicle program (Briody, 2013; Ferraro and Briody, 2013; Briody, 2010; Briody, Cavusgil, and Miller, 2004) but not yet about the other two organizations.

\section{Intimate Apparel Firm}

Our mixed-methods approach was designed to examine the robustness of links in the value chain (i.e., design to marketing to retail to shoppers and end users), assess the effects of organizational history and culture on sales, and explore the relationship between customer preferences and practices on corporate strategy. We conducted 22 interviews with managerial and higher-ranking executives (lasting one hour on average), nine interviews with managers of company-owned outlet stores, and informal discussions with 
store clerks and store managers at retail locations around the U.S. We gathered data from 26 in-home interviews and home tours (lasting 90 minutes on average) with women in seven U.S. cities, and two freelisting exercises with 10 of these women, to document the cultural categories through which women understood intimate wear. We also conducted in-store participant observation with shoppers to understand how women understood and valued the intimate wear they encountered - to understand what Desjeux and Zheng (2012) call the product itinerary: "the product in the context of its purchase and use." These methods, along with exploration of the firm's website and its competitors' websites, helped us understand how and where corporate and consumer views differed.

Because five researchers were involved due to the geographical spread of the project (including Erickson and Briody), we used a daily blog to communicate and discuss our initial thoughts and experiences. We shared our blog with our in-company partners. Two of us took the lead in analyzing the ethnographic material. We used content analysis to identify salient themes and patterns from the interviews and observations, comparing them with the blog discussions, and validating them with the views and experiences of other researchers and with our in-company partners.

\section{Global Vehicle Program}

This project, carried out by a sole in-house researcher (Briody), was designed to explore the overall effectiveness of a GM global vehicle program in its engineering phase. Ninety-one employees working at one U.S. location participated in interviews that lasted one hour on average. The interviews focused on the program's activities and issues, as well as on ideas for improving program performance. To gain an understanding of the ways technical and organizational-culture issues were negotiated, observations of 23 of the program's engineering and business meetings occurred; these meetings took place in large conference rooms and lasted 3.5 hours on average. Program documents were also collected. Finally, 26 presentations were given to members of the global program as well as the senior leadership across the corporation to validate and expand upon the findings and recommendations.

This research design allowed the comparison of interview data with both observations at meetings and program documents. The analysis was intended to be inductive and iterative due to the organizational and technical complexity of the global program. Content analysis was the key analytic technique used to capture cultural themes. Validation occurred both through one-on-one discussions and large-scale presentations.

\section{Hospital}

Seven researchers (including Briody and six hospital employees) used a variety of ethnographic methods in their project to improve patient hospital experiences. The data collection included 101 interviews with hospital staff and leadership, 51 meetings involving hospital personnel, and 46 observations on nursing floors, in diagnostic areas, and in waiting rooms. On average, the interviews lasted about 45 minutes, the meetings about 80 minutes, and the observations about 75 minutes. Our focus was on understanding the current state and eliciting the ideal state of the patient experience, as well as figuring out what aspects of the patient experience were working well, and those necessitating improvement. The project scope did not include direct interactions with patients per se because the project sponsors believed they already understood the patient experience from earlier projects; instead, they wanted to learn about the patient experience based on staff observations and perspectives. However, some of our interviews were with hospital employees who had been hospitalized or whose family members had been hospitalized.

We used three techniques to analyze the hospital data: content analysis of the qualitative data, discourse analysis of tape-recorded hospital meetings, and statistical analysis of key variables. We validated our findings through the use of different methods, data sources, and members of our research team. For example, we were able to compare our ethnographic results with the findings compiled from patient focus groups conducted two years earlier. 


\section{BACKGROUND}

\section{Rationale for Organizational Comparison}

All three organizations have headquarters in the U.S. As such, they share certain structural and relationship-based attributes. First, each organization is embedded within a layered corporate hierarchy in which sharp distinctions exist between the senior leadership team and all other employees. For example, an employee from the intimate apparel firm stated, "The fifth floor (which houses the senior leadership team) says that they look across for opportunities for people. But someone has to represent and sponsor you." Second, status, authority, and power matter enormously within the various functions and divisions associated with the three corporate hierarchies. Third, salary and career path are tied to these functional and divisional silos, with little cross-silo job rotation. The end result is that employee allegiance and daily social interaction is primarily focused within one's own silo. These structural and behavioral features were confirmed in the expressions employees used to describe their place of work and the jobs they performed. We routinely heard phrases and terms such as "turf wars," "fiefdom," "tribe," "territory," and "handoff" in all three organizations.

\section{Marketplace Challenges}

Employees associated with each case recognized that the external environment surrounding their organization was in flux and having a direct effect on their organization's performance. They were able to articulate specific pressures that heightened concerns about their organization's long-term competitiveness regionally (hospital), nationally (intimate apparel), and globally (vehicle program). Employees pointed to the necessity of innovation - whether in organizational processes or products/services or both, while complaining about the difficulty of shaping a coordinated response to emerging external pressures. Additionally, they specified the importance of the customer perspective, recognizing that favorable customer evaluations of products/services lead to return customers and enhanced image in the marketplace.

\section{A Corporate Strategy to Compete in Retail}

Revenue from the intimate apparel manufacturer had been flat for several years prior to the study, except in 2008-09 when it took a deep dive due to the recession. Part of the company's mission at that time was to "sell more, spend less, (and) generate cash." There had been several rounds of layoffs to cut costs. Executives and brand-managers in this global, U.S.-based apparel firm sought to understand women's changing needs for intimate apparel (e.g., younger women wanted bras earlier in their lives, obesity had been on the rise since the 1960s [NIH, 2012]). A key competitor firm, Victoria's Secret, had emerged as a market leader, pressuring the company to reexamine its positioning, retail approaches, and product offerings. A decision was made to produce women's bras and panties that were largely white, beige, or black, and which would be sold primarily through the company's key retail outlets: big-box retailers like Walmart and Target and mid-tier retailers like Kohl's and Marshalls.

\section{An Experiment in Global Engineering}

The establishment of global vehicle programs at GM resulted in part from a desire to achieve global economies of scale in product development, thereby reducing costs and improving profitability, quality, and lead time. An initial attempt to launch a global program had failed. However, senior management believed that a single vehicle underbody could be developed to serve as the platform for numerous car models; these models could then be adapted for different geographies, terrains, and regulatory requirements. As such, global programs were experimental. Senior leaders assembled three engineering units associated with multiple markets worldwide to do the program's development work. In this early engineering phase, key program personnel were located in or re-located to the U.S. 


\section{A Decision to Improve the Patient Experience}

Changes in U.S. health care policy have affected the view of the physician-patient relationship and the delivery of patient care. In response to the passage of the Affordable Health Care Act, and despite the uncertainties surrounding it, the hospital began a concerted effort to plan for changes in reimbursement rates, install and train staff on various forms of health IT, and put in place strategies to cope with shortages of primary care physicians. Of immediate concern was the loss of millions of Medicare dollars if patient satisfaction scores did not improve significantly. The hospital administration set aside resources to try to create and sustain a patient-centric hospital culture.

\section{MODEL OF SYSTEM-WIDE INNOVATION}

We present our model of system-wide innovation success to orient and guide the ethnographic descriptions of our three silo-ed organizations. The model consists of five organizational-culture features (See Figure 1). First, collaboration is an essential part of the model. Without organizational members working cooperatively and across organizational units (or silos) together, the innovation would not be sustained. Second, leadership buy-in - support for and advocacy of the innovation -matters for systemwide innovation. Third, structural change in the organization's functioning occurs. Such changes might include reporting relationships, roles, networks, use of incentives, and organizational rules. Fourth, work practice change, such as what work tasks are done and how these tasks are done, contributes to successful system-wide innovation. Finally, the model incorporates a feature we term evidence of benefit. This element includes demonstrable evidence of the innovation's advantages including cost, time, quality, and customer satisfaction. We derive this model inductively and iteratively from the ethnographic material.

\section{FIGURE 1}

\section{FEATURES TIED TO SYSTEM-WIDE INNOVATION SUCCESS}

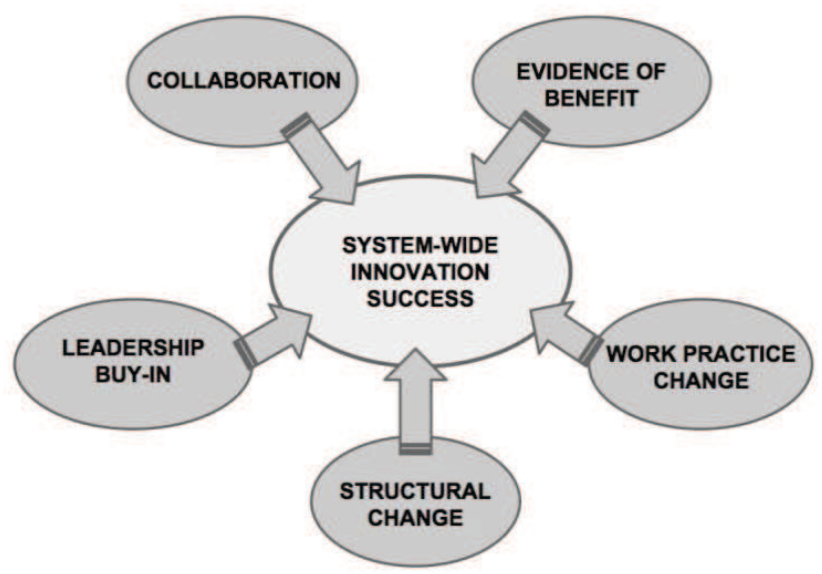

\section{INTIMATE APPAREL FIRM}

\section{Looking within Silos: "Bras Don't Talk to Panties"}

The intimate apparel firm was a bricolage of brands that had once been independent. Managers, merchandisers, planners, and sales staff had not previously been housed under the same roof prior to spinning off from a holding company about five years before our study began. Management resided on the fifth floor at the top of the office building, recapitulating in physical space the social and power distance between upper management and all other employees. Brand managers, planners, and other workers inhabited the corporate workspaces, laden with racks of sample products and display prototypes, 
spread out on the third floor of the building. Designers were located in the historic garment district in New York, more than an hour away by plane from corporate headquarters.

While there were several other work units corresponding to specialty products like men's underwear and so-called "active wear" designed for exercise, sport, and outdoor activities, the two key players in our study were the bra department and the women's panty department. These two groups had separate managers. Bras were the profit center for the company and included old-line brands dating from the late 1920 s, one that emerged in the 1940s, and a well-known figure-enhancing "push-up" line that emerged in the mid-1950s. Each bra line had its associated line of panties but the panty lines responded to the color and fabric choices that were set by the leadership in the bra division.

Although bras and panties were located next to one another, tension between the two product categories was frequently mentioned by the panty group members and by sales and field service staffers. One newly-hired manager said, "We don't meet with panties, and we don't meet with other bras. They are on my floor, but we are not talking among ourselves. We don't feel we are competing, but we don't talk about what worked well ... It is kind of a silo here." A member of one of the bra teams said that they work well as product teams (within their silos), but between teams (across silos) they work "very independently of each other, too. It's not competitive or anything, but we are so different from one another." Packaging or labeling issues were resolved at the brand level, and coordination among and between brands, like the interaction among and between bras and panties, was infrequent and guided by individual initiative. These bra and panty teams worked separately on projects for their individual brands, were ultimately responsible for the sales results that stemmed from their departments, and had to get permission from higher-ranking leaders for any product changes. Even when teams wanted to communicate or transfer (e.g., ideas, product) across different teams (or "businesses" or "worlds" as some people called them), "We can't. Everyone still has different systems. It's like transferring to a different company."

While we cannot describe the organization as a whole since it includes complex international supply chain units and other brands that were not the focus of our study, we do know that in women's intimates, matching sets was an issue for many shoppers and for many managers. Product development, point-ofsale merchandising, and manufacturing variation (e.g., dye-lot, fabrics, garment construction) were implicated in the differences between bras and panties. Bras are more difficult and expensive to produce than are panties, and offer the company higher margins. Bras are most often sold on hangers at retail; panties are generally packaged - though the competition offers "table programs" from which shoppers can mix and match individual panties laid out on a table, and some of the company's outlet stores offer this option. Although these products are made differently, in different manufacturing plants, those differences are attenuated at retail and in the consumer's experience. Surprisingly, in-store mannequins generally featured matching sets in both company-owned stores and in department stores like Macy's. And point-of-sale information such as garment tags and packaging graphics often featured matching sets, suggesting that the company was both driving and responding to a customer preference. At one flagship department store in New York, matching sets had been put on mannequins only to be taken down; the store was unable to obtain enough matching sets from the manufacturer. For at least some of the company's bra and panties lines, a limited number of matching sets were available so some coordination across categories was evidently taking place. But at retail, they were rarely in stock where and when customers wanted them.

We heard similar issues from managers working with an allied direct-sales organization that featured women's intimate wear in their catalogue offerings, and the same concerns from on-line sales managers. They could not get enough matching sets. Some managers felt matching sets were really important, while others, primarily upper management, did not seem to see them as a priority. The inability of different corporate units to develop and market bras and panties in a more coordinated way also was reflected in the spatial layout of the sales floor. Intimate apparel departments have separate sections for bras and panties; within those sections, our intimate apparel firm would have its bras displayed separately from its panties. In addition, the inability to both find and purchase matching sets was reflected in the frustrating experiences reported to us by women during the in-home interviews; these women were the ones who were ultimately affected by both the silo-ed organizational structure of the firm, the decision to offer only 
limited runs of matching sets, and the difficulty of finding those matching sets at retail. One of our inhome interviewees encountered this problem and commented with both surprise and annoyance, "Why can't a big company like this figure out how to manufacture enough matching sets?"

\section{Looking across Silos: Keeping a Lid on the Silos Helps Maintain the Status Quo}

Although the product moved from manufacturing through marketing, distribution, and in-store placement with carefully aligned point-of-sale materials and promotional schemes, information about what was happening along this value chain depended on the openness of borders between organizational units. Sales teams engaged in cross-functional meetings and idea-sharing with one another and with the merchandisers whose product was available in the stores that each sales person supported. But these sales professionals also acknowledged that bras and panties, and different kinds of bras, "do not do crossfunctional meetings." One sales staffer said that although he had been there for more than five years, he could not talk directly with a designer. Instead, he was required to talk to someone in merchandising, who would contact the designers. "The designers," he said, "will design what they think is right." Even when management teams have design ideas and push them up to New York, their concepts are not well received. It is, we were told, "pushback from the designers as to why they couldn't do it." Little if any cross-functional teaming occurred unless it related to production runs and general product availability.

Listening to customers, however, is part of the daily job for two kinds of staff: store managers who operate the company's own outlet stores that are scattered around the U.S., and "field support" team members who are responsible for visiting the big-box and mid-tier retailers. Tellingly, there is no formal communication opportunity between these two customer-focused groups. The retail store managers gain a high degree of awareness through their daily interaction with customers in their stores. Their concerns, drawn from a separate study, included the difficulty of obtaining matching sets. As one manager pointed out, "One of the things we can improve on is bra/panties sets to match ... people love to have matching sets."

The field support team is in direct contact with retail customers but there is no institutionalized way of drawing upon their insights for the product and marketing strategies that are in play at headquarters. The role of the team includes tasks such as making sure that displays are correctly set, that local retailers get their questions answered, and that local promotions are correctly implemented. When working on a display in a store, field support staffers take pride in visiting with customers, helping them with fit and style selection, and doing their best to act as in-store sales staff. The manager of this group, who said her input was not part of higher level management discussions, calculated that about 40 percent of her group's time was spent selling product to women at retail. When this manager began working for the company, she had a $\$ 14 \mathrm{M}$ budget and over 300 staffers. At the time of the study, she had less than half the money and 177 staffers. Her staff does not have computers and they file their reports on paper - something that she hopes to change. She stated, "The [field support] staff was there to put out stock and not think about the customer." However, she wants her staff focused on customer needs and on selling. Input from this manager's team was not seen or used as a resource. She stated, "No one uses our group as much as they should."

One other example of cross-silo interaction involved two different silos: sales and bras. One highlevel sales person, call him Jim, was frustrated with the complexity of the bra offerings he was pushing out to the big-box retailers. He pulled out a bra from one of the lines in which he had done well in a prior year and asked that the bra be scaled up to fit larger women; larger sizes were an important part of the target in big-box retail. The woman in charge of the old bra, call her Emily, did not see a benefit in a restyling and up-sizing since the brand was not sold in big-box retail. In other words, increased sales would not benefit her bottom line. Her colleague, whose products were sold in big-box, responded that she would have to talk to Emily whose bras were sold "upstairs" in department stores and not in the lowerpriced big-box retail space. Emily was the manager who had just told the sales executive Jim that his idea was not of interest. In response, Jim said he "went over their heads" and took his idea to the division manager who moved the idea of the scaled-up bra forward in 12 months and shaved six months off the usual product-development cycle. "I'm throwing years of credit out the window if I fail. My ass is on the 
line. Not a lot of people will walk out on a limb." Jim ended the story by saying that the company "will ship 250,000 units of that bra" in the current year. Leapfrogging silos in this way demonstrates the absence of institutionalized systems for sharing information and taking action in response to market needs.

\section{Intimates' Mixed Outcomes}

The intimate apparel company sees its greatest margins from sales of products that are packaged in plastic like panties and sold at big box retail as a commodity. Yet our research showed broad dissatisfaction not only with the difficulty of finding matching panty and bra sets, but also with finding the combination and correct size, style, and color. The only people who enjoyed shopping for bras were those who could afford shopping at high-end boutiques or those younger consumers who were Victoria Secret loyalists. It seemed the intimate apparel firm had a formula that was meeting its financial needs without having to address the serious organizational challenges presented by 1) sewing together formerly independent brands, 2) linking the highly-independent design teams with the teams responsible for merchandising, marketing, and selling, and 3) gathering and using input from interface units (e.g., field support, on-line, outlet stores) and shoppers. The outcomes related to the innovations were not all negative, but they did not allow timely response to market needs. Some matching sets were available, some of the time, so there must have been some collaboration. However, the firm did not make enough of them because they weren't committed to the concept. One recent earnings report from the company indicated that in recent years there has been an effort to move away from the commodity-based approach, and to upgrade the panty programs, generally, and they say this has been successful. While we were there, consistent and institutionalized pathways out of the silo-ed bra/panty world simply did not exist.

\section{GLOBAL VEHICLE PROGRAM}

\section{Looking within Silos: Organizational Processes and Practice Vary}

The initial interview with a marketing manager offered a window into GM's organizational-culture differences which coincided with its silo-ed corporate structure. The marketing manager was affiliated with Adam Opel AG the German-based engineering unit involved in the global program. He commented, "You should have been at that meeting today; it was a classic! I've had such a terrible morning. I'll have to tell you about it. It's just so frustrating!" He brought up two issues. First, he pointed out that in Europe, people

try to get things done in a quick, direct way. Everyone here (in the U.S.)

tries to hide behind a process. The process tells you what step to do next.

In Germany, we go to A or B to get something done and if that doesn't

work, we do it ourselves. I've seen a lot of people put up processes and

not follow them at all in the U.S. We need to learn about processes but we need to produce results.

He quickly followed with another comment about the American-run meetings he had been attending that were "completely unorganized with no purpose." This manager was used to a formal meeting agenda which would include "what decision you want made" based on a "one pager" submitted well in advance of the meeting. At these meetings, minutes were taken. When meeting attendees later received the minutes, all decisions were summarized. (See Ferraro and Briody, 2013, p.166-172.)

In subsequent discussions with program participants, it became clear that the purpose of meetings, the content covered, their format or style, and the amount of time allocated to them differed by engineering unit. For example, Small Car Group, one of the American units, preferred spending most of the work week in meetings since that was where information was shared and issues discussed. However, the other American unit, Saturn, preferred to keep meeting times to a minimum and to use a focused format and agenda for developing consensus on issues. All three units spent some time each week working independently to ensure that their customer requirements were part of their vehicles and to strategize how those requirements should be incorporated into the vehicle underbody. 
Over a period of a few months, the interview and observation data also revealed that each of the three engineering organizations employed a particular decision-making model. Small Car Group used an adaptation of the majority-rule model known as majority preferred. Individuals would "pitch" their ideas, advocating for their views in the hopes of securing "buy in" from other members and the unit's leader. Individualism was quite important to this overall process. The majority viewpoint typically prevailed unless the engineering leader opted for an alternative.

Saturn's decision-making model was based on 100-percent consensus. All engineering unit members had to "buy in" to a particular decision or there was no decision. Important to this unit were notions of equality and democracy. It could take a significant amount of time to review all of the input and align all member views. To assist with that process, members used the following rule of thumb: If you are 70 percent comfortable with a particular decision, you must state that you are "in," meaning you are in favor of the decision. In the event that the engineering groups were unable to reach consensus, they would approach a higher ranking group within Saturn to assist them with the decision.

Opel's model was largely dependent on what the "leader" decided. Known as the leadership-driven model, it was the leader's responsibility to make the call. (Leaders, of course, were present at all levels of the hierarchy and had varying levels of authority based on their role.) Nonetheless, decisions were not made in a vacuum. Instead, the leader solicited input from various sources. Program participants indicated that they were able to offer their perspectives or an assessment of a particular proposal freely and honestly if they were asked; they supported their views based on "data" they had compiled. They did not offer input if they were not asked. (See Briody, Cavusgil, and Stewart, 2004, p.426-8.)

\section{Looking across Silos: Low Levels of Cohesion and Authority Challenge Collaboration}

The challenges of a global vehicle program emerged only when two or more of the three engineering groups began working together. The Opel meeting style clashed with what the Germans perceived as the "American" meeting style. Initially, the meeting differences appeared to be largely an annoyance that created tension and communication difficulties. However, as the three units found that they had to interface more frequently and regularly, their differences resulted in work practice disruption. Program participants seemed at a loss for how to run program meetings when more than one engineering unit was present. The default way was that associated with Small Car Group which was considered the "program lead." This unit had the highest status and the greatest power on the program because 1) it contributed about 80 percent of the vehicle program's members, 2) its car would be the first to roll off the assembly line, followed at 18-month intervals by the cars of the other two units, and 3) its leader was assigned the role of program manager for the entire program.

Decision-making differences only added to the difficulties and contributed to low levels of cohesion among program participants. No one seemed to understand that each engineering unit had its own assumptions about how decisions were made. Instead, participants only recognized that decision making was painful and wondered why the others did not "think" like they did. Moreover, it was almost impossible to get all three units to reach agreement on a particular decision. Sometimes two of the engineering units would agree and attempt to force the third unit to comply. The latter would be challenged to "put on the (program's) hat," meaning that it should "be a team player" and go along with the majority view.

The reaction by the dissenting unit typically included an explanation for why it was unable to comply with the proposed decision. For example, Opel often used marketing data to point out differences in customer expectations and justify the fallacy of global programs. The dissenting unit would then seek the support of its own senior leaders to intervene on its behalf and reverse the "decision." Often high-ranking senior leaders of the dissenting unit would agree. If the other two engineering units continued their pressure to conform to the majority view, the dissenting unit's senior leaders would make a credible threat to "pull out of the program." Such a threat undermined the authority of the program manager and threw the program into a period of ambiguity and uncertainty. Developing cross-unit collaboration and a team spirit was inhibited as team members realized that appeals could be made through their respective chains of command. 
A high profile example of this type of conflict involved moving the cowl forward (i.e., the top portion of the vehicle body attached to the windshield). This issue appeared as the vehicle program approached its first "Concept-Initiation" milestone, a key decision point in the product development process. Opel's marketing arm was concerned that the car's styling would look "outdated" and would not be able to compete successfully with one particular group of Mercedes vehicles. The Opel proposal was to move the cowl forward by $75 \mathrm{~mm}$. As one of the German employees stated,

(The vehicle program) was close to being canceled. (The program manager and the lead engineer for Opel) were told there was one chance: if they changed the styling to (be like the Mercedes) vehicles, maybe Opel could stay in. (Opel's) marketing pushed it and won ... (The program manager and the lead engineer for Opel) agreed to it in Germany and they let us know by phone calls. They were forced to make a decision.

In the first few weeks following the decision to move the cowl forward, work was done to estimate the engineering and timing impact of this architectural change. Continued discussion of the pros and cons of the change ensued over several weeks. Finally, the program manager was reported to have intervened stating, "This decision has been made." At about the same time, a senior German leader visiting from Germany, commented, "(The cowl forward change) suits us all." These statements by both the program manager and the senior German leader signaled that this particular issue had been settled.

\section{A Failed Experiment}

The decision-making dilemmas that plagued GM's global vehicle program had important effects. First, management credibility was called into question when the template for the vehicle program system was inconsistent with day-to-day realities. This template emphasized the role of the program manager as a "strong program manager," establishing expectations that all vehicle programs would be managed differently than they had been in the past. Senior leadership intervention violated the envisioned global program structure in which the program manager was "accountable for the program's profitability and performance." When program personnel and others beyond the program saw that the template was largely disregarded in favor of the traditional autonomy and authority of the individual (silo-ed) units, they judged the new vehicle program structure quite harshly. The vehicle program template was branded as just another "program of the month."

Second, decision-making delays resulted, rendering the program's mantra "timing is sacred" largely meaningless. Decision-making delays were the result of the changeable authority of the program manager over product decisions and disregard for the product development process. The vehicle program team, faced with numerous threats of program cancellation, had to revisit, and then remake, decisions. There did not appear to be any particular mechanism to resolve an issue "once and for all" other than invoking the senior leadership of the firm. Revisiting issues, time after time, took attention and focus away from newly-emerging technical and business issues. The result was that the program was delayed, thereby lengthening, not reducing, lead time. In the case of the cowl forward issue, the program lost six months due to the extent of rework on the architectural changes; it also added a significant increase in the program's costs. (See Briody, 2010 for another example.)

Approximately two years after the global vehicle program was initiated, it ended. First one and then the second engineering unit made the decision to "pull out" of the program, thus rendering the concept of a global partnership and cross-silo collaboration a failure. It was a high stakes experiment that cost the corporation an estimated 2.2 million vehicle sales, threatened the long-term viability of global vehicle programs, and called into question the corporation's future as a global manufacturer. 


\section{HOSPITAL}

\section{Looking within Silos: Choices Are Made Locally}

A recent innovation for the hospital targeted staff-patient interaction; implementation was anticipated to be hospital-wide. AIDET (in which $\mathrm{A}=$ Acknowledge, $\mathrm{I}=$ Introduce, $\mathrm{D}=$ Duration, $\mathrm{E}=$ Explanation, and $\mathrm{T}=$ Thank You) was an acronym for a communication tool to help staff in their interactions with patients. Human Resource managers had introduced AIDET to middle management and some senior management during a leadership retreat; attendees were required to roll it out to their staff. A few months later, new hires were exposed to AIDET during their orientation.

Approximately one year after the leadership retreat, AIDET had been fully embraced by only two hospital units which reported to the Chief Operating Officer (though many other units also reported to him). EVS (Environmental Services) and Dietary incorporated AIDET into their daily interactions with patients. They were led by an energetic EVS manager who was supported by her middle manager; her manager also oversaw dietary. She regularly reinforced the learning and use of AIDET through individual and group practice, discussion at meetings, and small laminated cards as reminders of the acronym. The EVS and dietary staff expressed their acceptance of AIDET through statements such as "It is part of our life (here)" and "... (it) helps patients understand who you are and makes them feel welcome." Later, this same energetic EVS manager helped extend Plant Engineering's use of AIDET by helping to adapt AIDET for use in interactions with nursing floor staff.

Reactions to AIDET by those working in non-compliant departments and floors varied. One staff member commented, "Just another stupid customer service program - won't be effective until our culture changes." A second offered, "Reviewed several weeks ago and don't remember the material." A third stated, "It is not applicable to my job duties" while a fourth indicated, "I like it but I don't think we need to be waking the patients up to do AIDET." Yet, staff members who participated in a cross-silo patient experience team and who were involved in the training and assessment of AIDET use found the rollout of the innovation problematic. There seemed to be no willingness to require staff to use it. As much as they tried to push this innovation for over one year, their efforts fell short. AIDET adoption was not successful throughout the hospital. There was no hospital-wide mandate or set of incentives for using AIDET to help structure staff-patient interactions, nor was there any enforcement across the hospital silos by senior hospital leadership to use it. Indeed, there was no agreement on the value of AIDET. Comments on patient satisfaction surveys indicated patients' appreciation when staff interacted with them in friendly and empathetic ways, and dissatisfaction when they did not.

Communication is not only experienced face-to-face, such as in AIDET-based conversations, but also through experiences. Patient satisfaction surveys revealed the effect of wait time and delays: they resulted in negative perceptions of the hospital. Patient flow, the movement of patients to get the care they need in the hospital setting, has long been an issue at the hospital due to bottlenecks, staff shortages, and other issues. Combatting the patient flow problem occurred primarily within silos. For example, the Emergency Room (ER) introduced "direct bedding" in which the patient would bypass triage and go straight to an ER bed; triage would happen at the bedside. Nursing floors would bring on additional staff through the "float pool" or share staffing. Staff might pitch in and perform certain roles that they did not usually do (e.g., take a patient down for discharge).

However, staff reactions often included "blaming" and "finger pointing" as they expressed their frustration with those upstream units who turned patients over to them. The ER, in particular, was often the target of the blame. For example, one staff member stated, "Between 6:00-7:00 p.m. which is our change of shift, they want to send four patients up (to Unit X)...Well, damn it, patient flow has to do with the safety of ... we can't handle them!" The ER's actions, and subsequent actions on the floors, had downstream effects. An EVS staff member commented, "I don't think the floors understand ... that when they have five patients that are set for discharge and they put all five patients in the computer minutes after each other, how that really affects the flow from an EVS standpoint." In this example, EVS would be notified all at once that five beds were waiting to be cleaned. 


\section{Looking across Silos: Leadership Support and Incentives Can Foster Collaboration}

To help reduce patient wait time, the ER reestablished the mission of the Admission, Discharge, and Transfer (ADT) Unit. While the ADT had long been a unit of the hospital, it had been used most recently as an overflow unit after surgical procedures. After a restructuring in which the ADT became part of the ER, ER management conducted a series of pilot studies demonstrating significant reductions in patient wait time and improved patient satisfaction when the ADT was used for its intended purpose. Prior to that point, patients could remain in the ER for up to 20 hours, eight hours on average, depending on hospital capacity and census. One of the ER managers told us,

Our goal is to get those patients out of the ER. If that patient needs to be admitted and is stable, they can come up to the ADT unit. A physician will meet them there. The patient is in a private room. They are in a medical bed. They are allowed to have family ... And the staff up there will watch you and communicate ... (and) it opens up a bed in the ER for the patient in the waiting room. The next patient has somewhere to go.

Two aspects of the ADT required cross-silo collaboration. First, ancillary units serving the ADT agreed to provide the same quick turnaround times on diagnostic tests that they offered the ER staff; securing the physicians' agreement was critical to getting the ADT up and running. One of the ER managers told us,

I met with every manager before starting this study and said, 'Here's our plans. This is where we need to go.' And all of them were receptive - the pharmacy, radiology, lab. I said, 'We're going to have extra taxing stuff on you. We're going to expect you to turn over these orders relatively quick. This is going to add a huge workload burden on you. Is this something you're willing to do?' None of them blinked an eye at it. They all said, 'Let's go for it' ... They've all jumped in and tackled the issue. It's been a group effort.

Second, the ER managers created an additional ADT service called the "roving nurse." One of the managers commented, "That nurse goes through the house (any hospital floor) and ... facilitate(s) discharges. If we're at $100 \%$ capacity, that nurse tags another nurse usually provided by float pool. And there's two nurses now roving around ... So they are averaging about 12 discharges a day." In turn, the "roving nurses" help free up the floors.

The repurposing of the ADT did create tension with other hospital units. Staff were used to using the ADT as a "holdover area" when the hospital's census was high; eventually that option was no longer a possibility. Some nursing floors refused to have the roving nurses assist them with discharges and, at the same time, chose not to send their discharged patients down to the ADT lounge to wait for family members for pick up. However, the managers had strong support within their chain of command. Over time such resistance lessened because "the floors are graded on how long it takes to get a patient out of the door so they see the roving nurses as a help to that process," one of the managers explained. Even members of the hospital's senior leadership, who were initially skeptical, ultimately accepted the ADT because it proved to be cost effective.

\section{Some Promising Results}

The ADT innovation fared far better than that of AIDET and resulted in the collaboration of multiple hospital units led by mid-level ER management. Their pilot studies and extensive experimentation with days and hours of operation over a long period of time resulted in a reasonably smooth restructuring. Over the course of its first few months of operation, the ADT was able to demonstrate continued reductions in patient wait time, more efficient and effective patient care, and improved hospital experiences.

One of the ER managers anticipated that if the ADT restructuring worked, it would be possible to create other similar cross-silo collaborations within the hospital. He reported, "We're really excited about it. And to me the exciting part is not just looking at what the ADT is capable of doing - is that I know we can replicate that anywhere in the building. And that's my ultimate vision of this ... to say, 'Yeah, we did 
it over here but you can do it over there." His belief has been borne out by other significant organizational innovations - all involving the ER and all leading to faster and better patient care. In all of these initiatives, multiple units had to participate to ensure success.

The most recent of these initiatives was launched after both ER managers had been promoted - one to head all of nursing operations and the other to head the ER and serve as the lead for the patient flow initiative. Together they were in a position to extend their focus on patient flow from the ER to the nursing floors. They gathered estimates from each floor of the number of beds they would need (e.g., based on anticipated admissions, surgeries, other procedures) during the busy nights mid-week. Initially the floors resisted compiling and providing this information. However, with the constant focus of these managers during afternoon "rounding," their clear expectations to the floors, good-natured interactions, and follow up with the "daily scorecard" to highlight improvements, resistance gave way to acceptance. The new nursing operations manager, in speaking with one of the floor staff said, "We're going to give you the support and resources ... If you see something that's not working, come back to me and let me know."

The two managers convened a small, cross-silo team which included nursing, ER, EVS, and others, to project the number of beds that would be needed at night and determine the appropriate number and type of staff to care for those patients. Staff participating in this Nightly Bed Projection Team found the problem-solving work to be engaging and empowering. They even turned their predictions into a game, making it into a fun activity. New members rotated into this team, thereby quickly broadening the staff's overall knowledge base. Over time, confidence grew in the value of the team's projections and the ability to plan accurately for staffing needs. This "data-driven" approach helped to remove much of the uncertainty that the floors faced. Moreover, the team was able to show that the number of patient comments related to wait time and the percentage of negative comments overall declined following the launch of the nightly bed projection meetings.

\section{INNOVATION PATHS}

In this section we explore what can happen internally within a silo, and organizationally across silos, as innovations are introduced. These cross-silo interactions had different progressions or paths and led to different innovation outcomes. For each of the ten paths below, we describe and depict the sequence of key organizational-culture features associated with each path.

\section{Paths to Innovation Failure}

Six of the paths resulted in innovation failure. They included the Global Vehicle Program path, the four paths taken to establish Matching Sets as part of the intimate apparel product line, and one of the AIDET paths.

\section{Global Vehicle Program}

The senior leadership came up with the idea for a global program, expecting that three of their engineering units would be able to work together. Yet, internal cohesion suffered as a result of differences in work practices and processes (e.g., meeting styles, decision-making models) and the seizure of authority from the program manager. Collaborations did form over specific engineering issues, but they were short-lived, only to be replaced by different alliances on other engineering issues. Resistance soared as senior leaders intervened in program matters, ultimately confirming that none of the three engineering units would be able to engineer its car models to appeal to its customer base. Any hope of achieving global economies of scale was dashed and the expectation that the three silo-ed units would become a collaborative and integrated global program was never realized (See Figure 2). 
FIGURE 2

THE GLOBAL VEHICLE PROGRAM'S PATH TO INNOVATION FAILURE

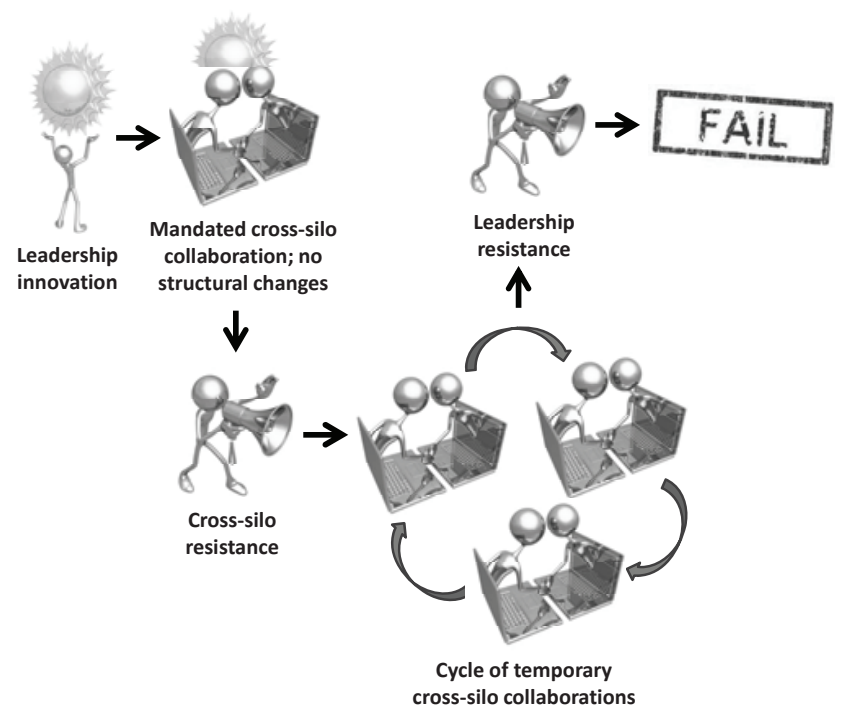

\section{Matching Sets \#1}

We identified four paths associated with attempts to collaborate on matching sets of bras and panties. Only one of the four paths experienced any success: some number of matching bras and panties were produced and sold. This effort required cross-silo collaboration throughout the product development process and in retail and on-line sales and marketing. At some point, leadership resistance to matching sets increased and they were never produced in sufficient quantities given the demand. When we interviewed executives, we received only a lukewarm reaction to matching sets. Interestingly, sales and marketing have continued to show models and mannequins wearing matching sets. Ultimately, this path resulted in failure (See Figure 3). As of this writing, bras and panties are only offered separately on the company's website. We found no matching sets.

FIGURE 3

A PARTIAL SUCCESS FOR MATCHING SETS LEADS EVENTUALLY TO FAILURE

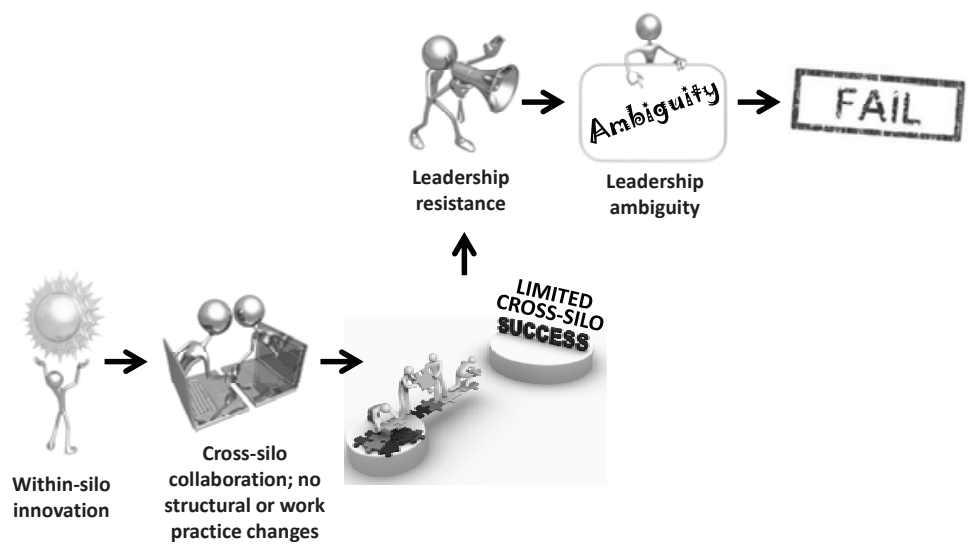




\section{Matching Sets \#2}

Among corporate employees, we found that cross-silo collaboration was envisioned but never materialized. Employees told us that they could not understand why there was not more teamwork among the bra and panty silos. Instead, employees found that they remained largely isolated within their own silos, which in effect prevented them from working together on joint projects such as matching sets. Corporate management resisted making a commitment to robust and ongoing cross-silo collaboration (See Figure 4).

FIGURE 4

\section{CORPORATE EMPLOYEES FAIL IN RAISING THE QUESTION} "WHY NO MATCHING SETS?"

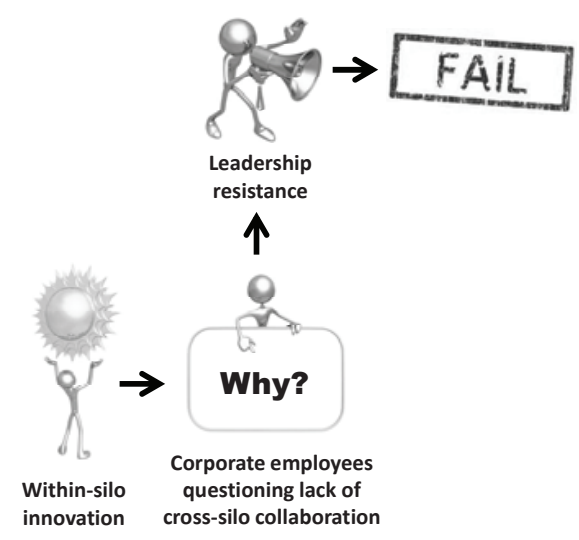

Matching Sets \#3

Another path consisted of input from customers to "front-line" employees such as those who worked in field services or in on-line sales. Our interviews with front-line employees revealed that customers with whom they spoke commented on the lack of availability of matching sets. Such customer input was passed along to the managers of these front-line employees where it typically received no traction (See Figure 5).

FIGURE 5

FRONT-LINE EMPLOYEES FAIL IN PASSING ALONG CUSTOMER FEEDBACK

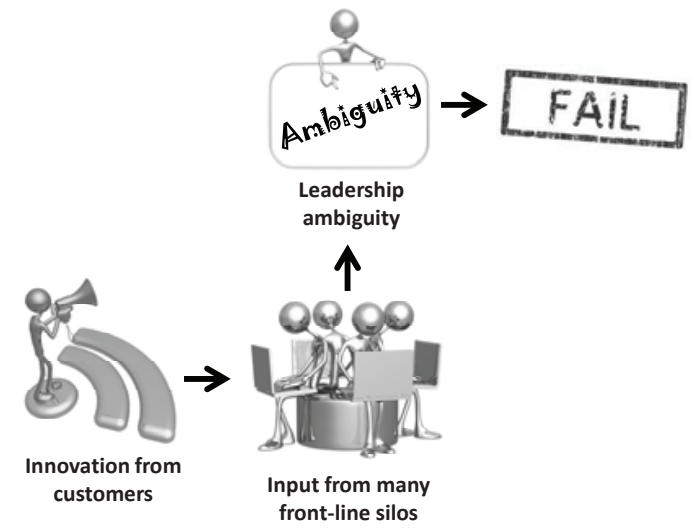


Matching Sets \#4

A final path involved our research team. Corporate as well as front-line employees shared their views with us on matching sets, as did store sales associates, and the many customers we interviewed. We sensed their keen frustration about an insufficient supply to meet demand. We reported these views and our recommendations to the management group sponsoring our project. As far as we know, no action was taken (See Figure 6).

FIGURE 6

RESEARCH TEAM ADVOCACY FAILS TO MAKE THE CASE FOR MATCHING SETS

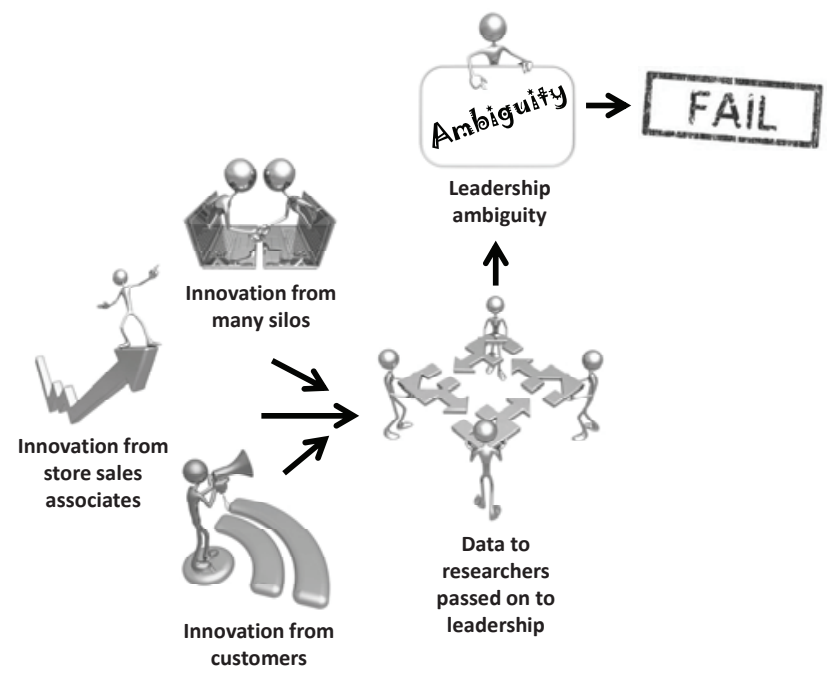

\section{AIDET \#1}

Our research team observed a predominant reaction to AIDET after hospital mid-level and senior management were exposed to it. A large number of hospital silos - particularly those in the business functions - kept their views on AIDET out of the public realm. Clinical care silos also seemed to ignore this initiative either because they believed their approach to patient care was already exceptional or because they did not value what AIDET offered. Over time these non-compliant units were able to disengage from the attempted AIDET implementation. We also noted that senior hospital leadership did not routinely mention AIDET in their communications; rarely did we hear them refer to it. Thus, leadership ambiguity characterized the bulk of the response to this innovation, which ultimately led to its demise (See Figure 7). 
FIGURE 7

AMBIGUITY SURROUNDING AIDET TIED TO INNOVATION FAILURE

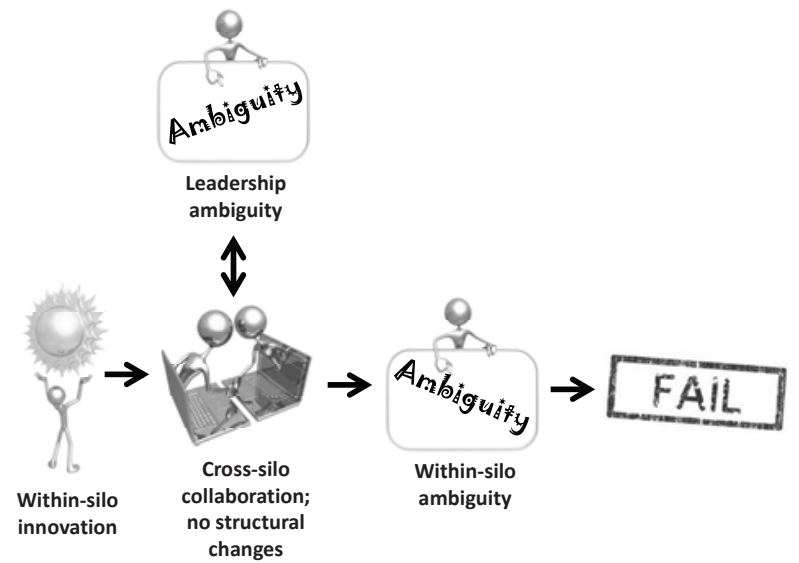

\section{Paths to Partial Realization of Innovation}

Two of the ten paths represented a partial success in terms of innovation path outcome. In one other AIDET path, the outcome represented a subsystem success. Employees in nonclinical roles with direct patient contact changed the way in which they interacted with patients. A second example of a partial success involved the scaled-up bra. Its accomplishments were limited to a one-time-only success.

\section{AIDET \#2}

Unlike the ambiguous reception AIDET received in most hospital silos, some silos fully accepted it. EVS and dietary services incorporated AIDET into their daily tasks. Their leaders conducted group training, on-on-one practice sessions with employees, and follow-up evaluations. These leaders also created incentives to reward employees who put this innovation to use. Members of the EVS and dietary silos received positive feedback from patients through direct verbal feedback as well as written comments on patient satisfaction surveys. One other silo, plant engineering, took note of EVS and dietary's achievements and received help applying AIDET to interactions with nursing staff (See Figure 8). While successful across selected silos, AIDET was never extended system-wide. 


\section{AIDET'S SUCCESSFUL INTEGRATION WITHIN SOME HOSPITAL SILOS}

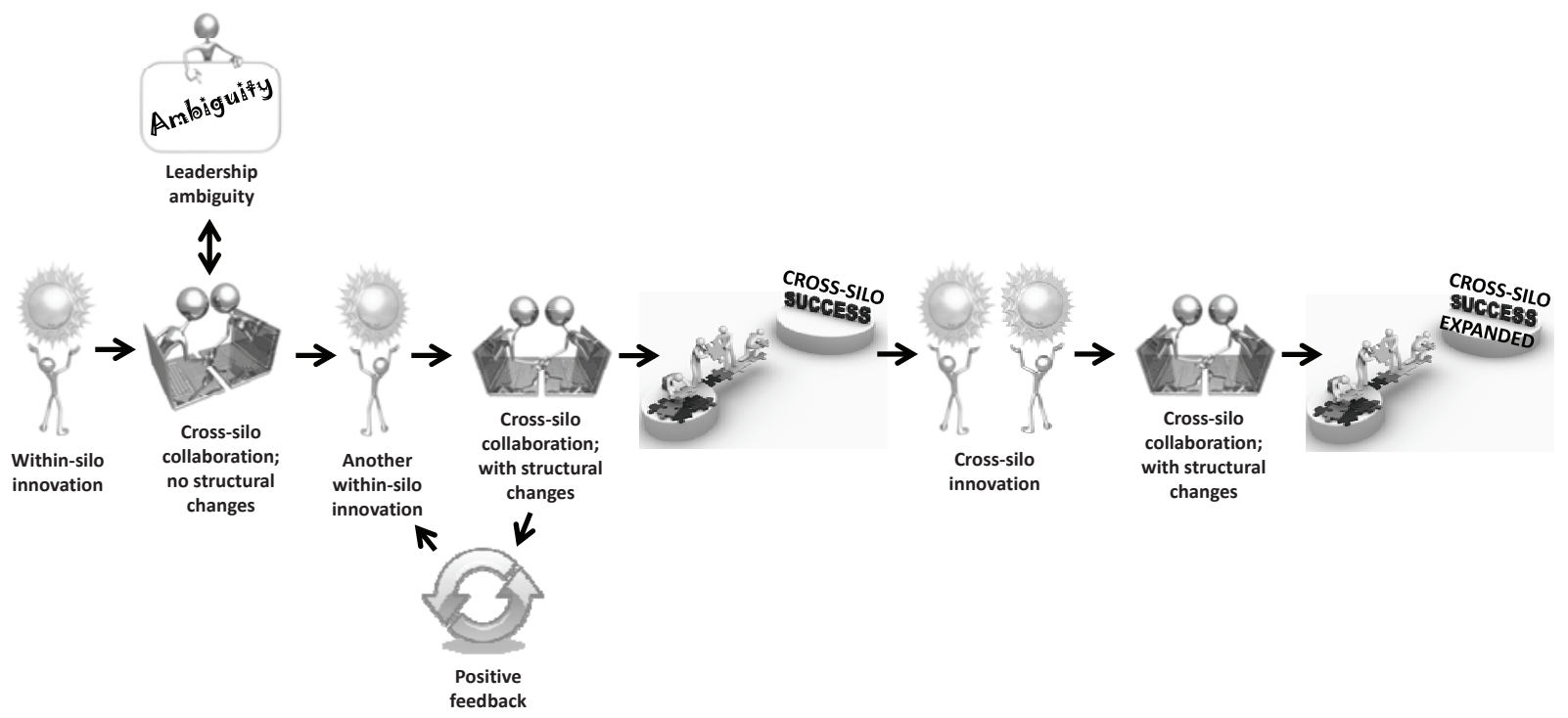

Scaled-Up Bra

We were told that it takes roughly 18 months to move a bra from the idea stage to placement on intimate department retail shelves. Doing so in about a year, as was the case with the re-sized and rebranded department store offering, did not come about because of an effort by management to bridge silos. It was done by breaking rank. It happened only after a high-level sales executive got no buy-in from the bra units. The innovation was pushed through when the executive who managed both bra groups agreed with the sales executive and took on the project. While the new bra was selling well, the innovation did not produce any organizational change and may have damaged relationships and future collaboration potential between cross-silo peers. This kind of silo-busting was rare and seen as threatening by some. It also produced no organizational or work practice changes other than adding to the corpus of stories that the sales executive could tell about the difficulty the organization has with responsive, timely product innovation. System-wide innovation was not achieved (See Figure 9).

\section{FIGURE 9 \\ THE ONE-TIME-ONLY SUCCESS OF THE SCALED-UP BRA}

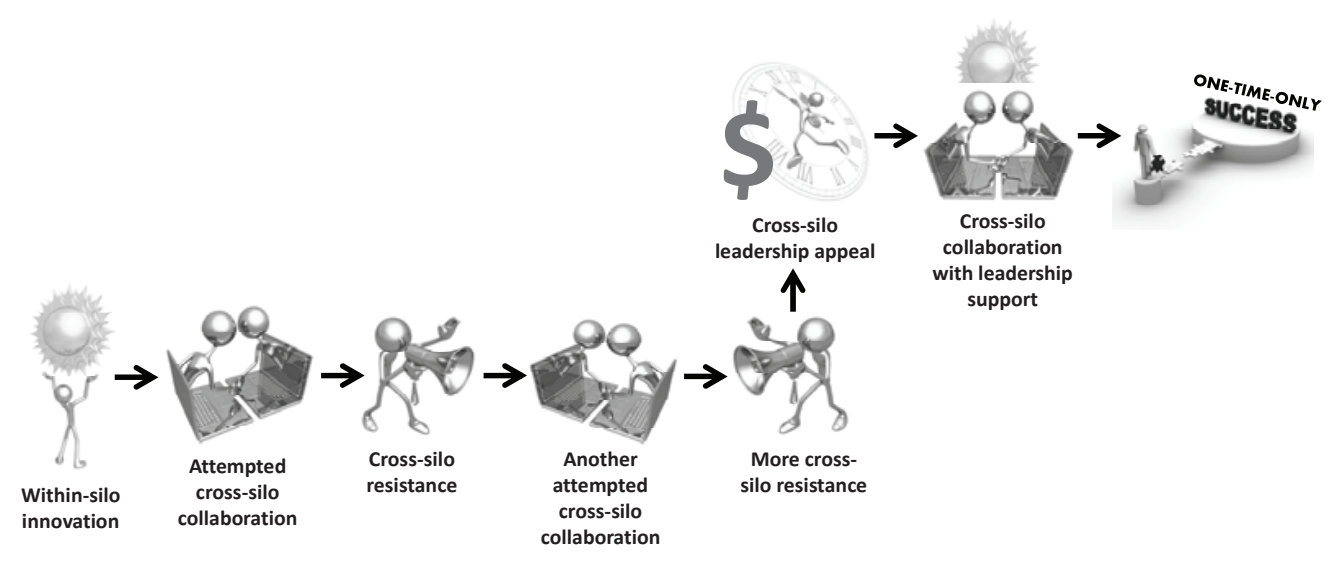




\section{Paths to Innovation Success}

We identified two paths to successful system-wide innovation among our group of ten. Both successes were part of hospital operations and led by the same middle management leaders. We identified within-silo, chain-of-command support for both innovations. Resistance emerged during the innovation process but was addressed.

\section{$A D T$}

Two ER middle managers were able to secure agreement from their senior leader to test out the ADT concept once a restructuring placed the ADT under the control of the ER. They approached all ancillary units to see if those units would be able to collaborate with the ADT and provide quick turnaround time on diagnostic tests. With the ancillary units' support, the ADT began its pilots. Most nursing floor resisted the help of the ADT's roving nurses until the floors were subjected to discharge metrics. Some senior leaders also resisted the ADT innovation arguing that it would not be cost effective; once the cost issue was overcome, senior leadership resistance weakened. At that point, the cross-silo collaborations between the ER and the ancillary units, and the ADT's roving nurses and the nursing floors, were able to get the full value out of the ADT innovation (See Figure 10).

\section{FIGURE 10 \\ THE PATH TO ADT'S INNOVATION-WIDE SUCCESS}

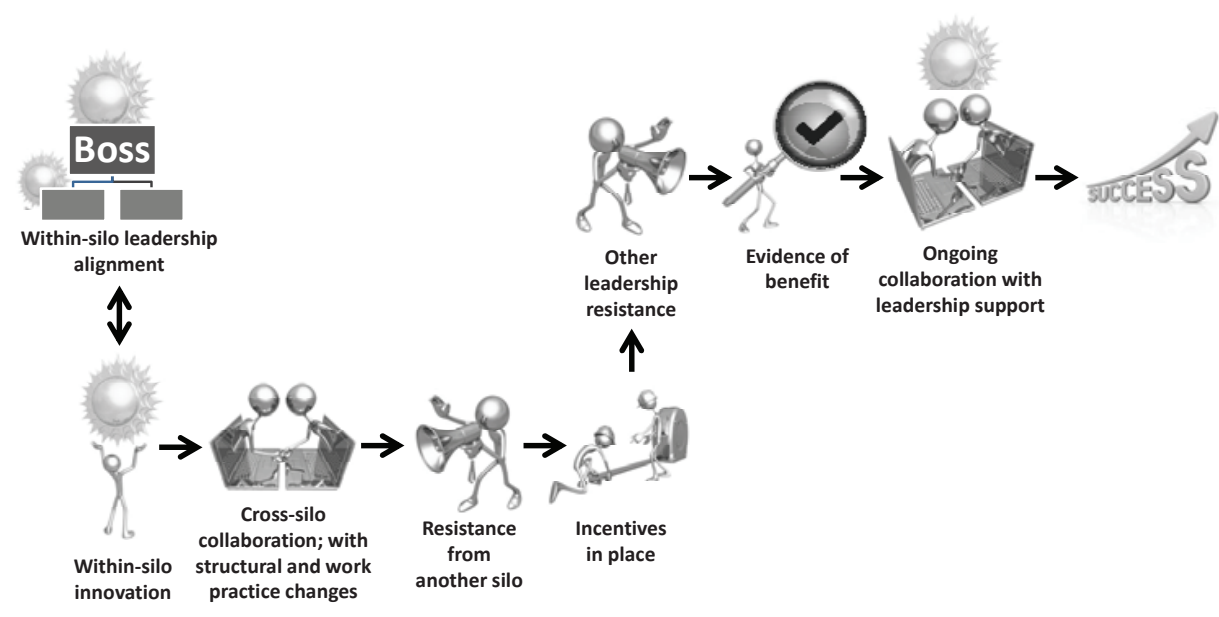

\section{Nightly Bed Projection Team}

This innovative team was created by the two middle managers who had led the ADT innovation and had been subsequently promoted. Now part of two different silos, the pair got support from the senior leader to whom they both reported. However, the two individuals then faced some initial resistance by the large silo composed of nursing floors; their request to the floors for anticipated and confirmed discharges was unusual and created additional work. They were able to break down this resistance by building relationships with the key nursing staff on each floor, and by taking the time to explain how the floors would benefit from the innovation. Soon the floors demonstrated their collaboration by having the numbers ready when the two made their rounds. With the floors' input, it was then possible for the Nightly Bed Projection Team to develop their projections, share them with other units (e.g., patient transportation, EVS), and determine the most accurate staffing ratios for the night. This system-wide innovation is ongoing (See Figure 11). 


\section{FIGURE 11 \\ THE SUCCESSFUL INNOVATION-WIDE PATH INVOLVING THE NIGHTLY BED PROJECTION TEAM}

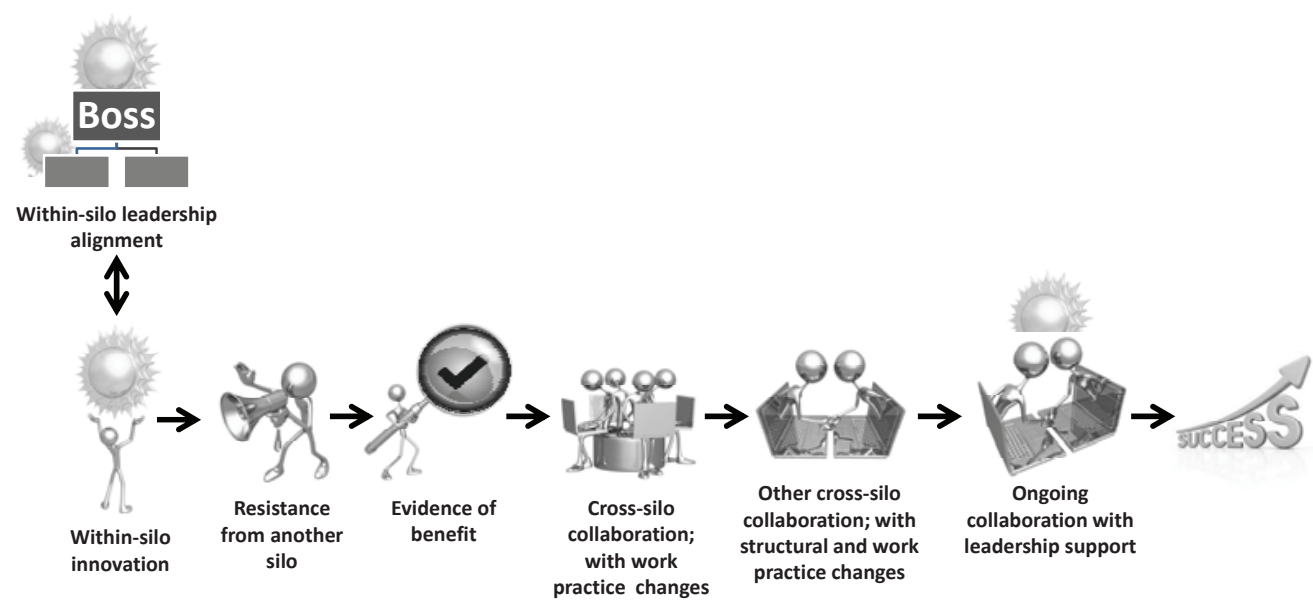

\section{ORGANIZATIONAL CULTURE AND INNOVATION OUTCOMES}

Our ethnographic exploration of the 10 paths provides both insight and nuance into innovation in siloed organizations. We created Table 1 as a tool to aid our understanding of the innovation process. Table 1 incorporates the five organizational-culture features modeled in Figure 1: collaboration, leadership buyin, structural change, work practice change, and evidence of benefit. Table 1 also includes the innovation path outcomes and the system-wide innovation outcomes. (Our analysis can be explored or tested for robustness by other researchers using alternate data sets, whether ethnographic or not.)

None of the five features listed in Table 1 presents a simple, straightforward, linear, explanation. Collaboration, for example, appears early (AIDET \#1) as well as late (scaled-up bra) during the innovation process. Sometimes it is mandated (global vehicle program) and sometimes it is not (ADT). Sometimes it lasts (AIDET \#2) and sometimes it is short lived (matching sets \#1). Sometimes it is temporary or sporadic (global vehicle program) and sometimes it is a constant (ADT). And, sometimes it never occurs (matching sets $\# 2, \# 3$, and \#4) while in other instances it emerges stronger after resistance has been overcome (Nightly Bed Projection Team).

The four remaining organizational-culture features also reveal a messy complexity. We see that if leadership buy-in wavers or is ambiguous, rather than being stable and clear, system-wide success is not achieved. If structural changes do not accompany the innovation, the implementation of the innovation is unlikely. Work practice changes also are important to innovation success. In the case of the ADT, the enforcement of the metrics related to discharge time forced a change in work practices; only then were nursing floors willing to accept the help of the roving nurses. Finally, when there is no obvious benefit to the innovation, the implementation of that innovation is unlikely. In fact, even if there is a documented benefit - such as in AIDET \#2 - the innovation may not expand system-wide. This pattern was confirmed recently at the hospital. Approximately 18 months after the introduction of AIDET, there is no longer any push to adopt it. As of this writing, one of the hospital managers indicated, "I hear very little from anyone about AIDET." 


\section{TABLE 1 \\ OPPORTUNITIES FOR INNOVATION BY SELECTED ORGANIZATIONAL-CULTURE FEATURES AND OUTCOMES}

\begin{tabular}{|c|c|c|c|c|c|c|c|}
\hline $\begin{array}{l}\text { Cases and } \\
\text { Innovation } \\
\text { Paths }\end{array}$ & Collaboration & $\begin{array}{l}\text { Leadership } \\
\text { Buy-In }\end{array}$ & $\begin{array}{c}\text { Structural } \\
\text { Change }\end{array}$ & $\begin{array}{l}\text { Work } \\
\text { Practice } \\
\text { Change }\end{array}$ & $\begin{array}{l}\text { Evidence } \\
\text { of Benefit }\end{array}$ & $\begin{array}{c}\text { Innovation } \\
\text { Path } \\
\text { Outcome }\end{array}$ & $\begin{array}{l}\text { System- } \\
\text { Wide } \\
\text { Innovation }\end{array}$ \\
\hline $\begin{array}{l}\text { Global } \\
\text { Vehicle } \\
\text { Program }\end{array}$ & $\begin{array}{l}\text { Mandated; then } \\
\text { occasionally, issue } \\
\text { by issue }\end{array}$ & $\begin{array}{l}\text { Only at outset; } \\
\text { then decreased } \\
\text { over time }\end{array}$ & $\begin{array}{c}\text { No due to } \\
\text { insufficient } \\
\text { changes so silos } \\
\text { reinforced }\end{array}$ & No & No & Failure & 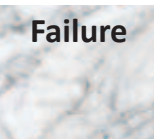 \\
\hline $\begin{array}{l}\text { Matching } \\
\text { Sets \#1 }\end{array}$ & $\begin{array}{l}\text { Some but short } \\
\text { lived }\end{array}$ & $\begin{array}{l}\text { Only at outset; } \\
\text { then decreased } \\
\text { over time }\end{array}$ & No & No & Unclear & $\begin{array}{l}\text { Limited cross- } \\
\text { silo success; } \\
\text { then failure }\end{array}$ & \\
\hline $\begin{array}{l}\text { Matching } \\
\text { Sets \#2 }\end{array}$ & No & No & No & No & No & Failure & \\
\hline $\begin{array}{l}\text { Matching } \\
\text { Sets \#3 }\end{array}$ & No & No & No & No & No & Failure & \\
\hline $\begin{array}{l}\text { Matching } \\
\text { Sets \#4 }\end{array}$ & No & No & No & No & No & Failure & \\
\hline AIDET \#1 & Yes & Ambiguous & No & No & No & Failure & \\
\hline AIDET \#2 & Yes & $\begin{array}{l}\text { Only certain } \\
\text { silos; others } \\
\text { ambiguous }\end{array}$ & $\begin{array}{l}\text { Only certain } \\
\text { silos }\end{array}$ & $\begin{array}{l}\text { Only certain } \\
\text { silos }\end{array}$ & Yes & $\begin{array}{c}\text { Ongoing } \\
\text { success across } \\
\text { selected silos } \\
\end{array}$ & $\begin{array}{l}\text { Partial } \\
\text { Success }\end{array}$ \\
\hline Scaled-Up Bra & Not initially & $\begin{array}{l}\text { Only a particular } \\
\text { leadership silo }\end{array}$ & Not initially & Not initially & No & $\begin{array}{l}\text { One-time only } \\
\text { success }\end{array}$ & $\begin{array}{l}\text { Partial } \\
\text { Success }\end{array}$ \\
\hline ADT & Yes & $\begin{array}{l}\text { Initially only } \\
\text { innovating silo's } \\
\text { leadership; then } \\
\text { resistance by all } \\
\text { others; finally } \\
\text { buy-in by all }\end{array}$ & Yes & $\begin{array}{l}\text { Not until } \\
\text { metrics } \\
\text { enforced }\end{array}$ & Yes & Success & Success \\
\hline $\begin{array}{l}\text { Nightly Bed } \\
\text { Projection } \\
\text { Team }\end{array}$ & $\begin{array}{l}\text { Yes after } \\
\text { resistance } \\
\text { overcome }\end{array}$ & $\begin{array}{l}\text { Initially certain } \\
\text { silos; then later } \\
\text { all silos }\end{array}$ & Yes & Yes & Yes & Success & Success \\
\hline
\end{tabular}

Table 1 illustrates that all five organizational-culture features are important to successful system-wide innovation in silo-ed organizations. These five features are associated with the two successes - the ADT and the Nightly Bed Projection Team.

By contrast, one or more of these features is missing in all remaining innovations. The innovations that we designated as partial successes incorporated some of these features during the innovation. For example, the scaled-up bra was produced through a collaborative appeal to leadership authority. However, this innovation did not represent a permanent change in either organizational structure or work practices, and damaged the potential for future collaboration with peers. Consequently, it was not sustainable in the long run.

The majority of the innovations were failures. For example, the global vehicle program floundered on all five features. Collaboration lasted only as long as it took to secure agreement on a technical issue. Structural mechanisms were inadequate to ensure program authority and no incentives were in place to create a cohesive team. Leadership buy-in, unexpectedly, increased the internal conflict and contributed to the program's termination. Finally, no evidence could be found that the global vehicle program innovation would lead to long-term success in its current configuration. 


\section{CONCLUSIONS}

Silos are capable of producing work within their own areas of routine expertise and can be both proficient and resourceful in getting their own work done. They help cut back on the "noise" or distractions from other units which can limit their efficiency. But when action is required that involves sharing, coordination, and cooperation across silos, particularly in response to external environmental change, silo boundaries become a problem to be solved.

Silo-ed organizations follow different paths when attempting to implement change. Sometimes different paths emerge associated with the same innovative idea. One or more of these paths might yield some success, although that success might be temporary or confined to a particular part of the organization. System-wide change involves a more comprehensive approach, more effort, and more organizational members to ensure it is successful. The variation in system-wide change is based on such elements as who initiates the innovative idea, the perceived priority and beneficiaries of the innovation, aligned leadership and employee support, complexities associated with workplace restructurings and changes in the nature of work, and the ease with which value from the innovation can be identified.

Cross-silo collaboration can and does happen; when it does, the boundaries between silos become less salient and in-group vs. out-group differences and conflict are weakened. Collaboration seems to work best when expectations about it are embedded within the organization's cultural rules, and when mechanisms are in place to support it. Yet, while collaboration is a necessary condition, it is not a sufficient condition to ensure system-wide success. Our data suggest that collaboration that occurs in concert or in tandem with four other organizational-culture features - leadership buy-in, structural change, work practice change, and evidence of benefit - leads to system-wide success. When those five elements are not present, it is likely that any success will be partial at best.

\section{ACKNOWLEDGMENTS}

We appreciate the comments we received from Maryann McCabe, Robin Beers, and Marc S. Robinson. Their ideas and suggestions helped to make the article stronger.

\section{REFERENCES}

Aaker, D. (2013). Spanning Silos: The New CMO Imperative. Cambridge, MA: Harvard Business Press.

Bandali, K., B. Niblett, T.P.C. Yeung, and P. Gamble. (2011). Beyond Curriculum: Embedding Interprofessional Collaboration into Academic Culture. Journal of Interprofessional Care, 25, 7576.

Bannister, F. (2001). Dismantling the Silos: Extracting New Value from IT Investments in Public Administration. Information Systems Journal. 11:65-84.

Briody, E.K., R.T. Trotter, II, and T.L. Meerwarth. (2010). Transforming Culture: Creating and Sustaining a Better Manufacturing Organization, New York, NY: Palgrave Macmillan.

Briody, E.K. (2013). Managing Conflict on Organizational Partnerships. In A Companion to Organizational Anthropology, D.D. Caulkins and A.T. Jordan, eds., Blackwell Publishing, Ltd., 236-256.

Briody, E.K. (2010). Handling Decision Paralysis on Organizational Partnerships, CourseReader (Internet Access), Detroit, MI: Gale.

Briody, E.K., S.T. Cavusgil, and S.R. Miller. (2004). Turning Three Sides into a Delta at General Motors: Enhancing Partnership Integration on Corporate Ventures. Long Range Planning, 37, 421-434.

Bundred, S. (2006). Solutions to Silos: Joining Up Knowledge. Public Money and Management. 26, (2), $125-130$.

Cash, J.I., M.J. Earl, and R. Morison. (2008). Teaming UP to Crack Innovation and Enterprise Integration. Harvard Business Rreview. November, 1-11. 
Cilliers, F. and H. Greyvenstein. (2012). The Impact of Silo Mentality on Team Identify: An Organisational Case Study. SA Journal of Industrial Psychology/SA Tydskrif vir Bedryfsielkunde, 38, (2), Art. \#993, 1-9. http://dx.doi. org/10.4102/sajip.v38i2.993.

Crossan, M.M. and M. Apaydin. A Multi-Dimensional Framework of Organizational Innovation: A Systematic Review of the Literature. Journal of Management Studies, 47, (6), 1154-1151.

Curtis, J.R. and S.E. Shannon. (2006). Transcending the Silos: Toward an Interdisciplinary Approach to End-of-life Care in the ICU. Intensive Care Medicine, 32, (15), 15-16.

Desjeux, D. and L. Zheng. (2002). The Itinerary Method: Comparing Intercultural Daily Life: The Case of Guangzhou, China. http://www.argonautes.fr/sections.php?op=viewarticle\&artid=422 accessed on November 14, 2013.

Diamond, M., S. Allcorn, and H. Stein. (2004). The Surface of Organizational Boundaries: A View from Psychoanalytic Object Relations Theory. Human Relations, 37, (1), 31-51.

Diamond, M.A., H.F. Stein and S. Allcorn. (2002). Organizational Silos: Horizontal Organizational Fragmentation. Journal for the Psychoanalysis of Culture \& Society, 7, (2), Fall, 280-296.

Ferraro, G.P. and E.K. Briody. (2013). The Cultural Dimension of Global Business, Boston, MA: Pearson, $7^{\text {th }}$ ed.

Foster, N.F. (2013). Designing Libraries in Liminal Space. Paper Presented at the American Anthropological Association Meetings, November 20-24, Chicago, IL.

Gulati, R. (2007). Silo Busting: How to Execute on the Promise of Customer Focus. Harvard Business Review, May, 1-9.

Herbert, C.P. (2005). Changing the Culture: Interprofessional Education for Collaborative Patient-centred Practice in Canada. Journal of Interprofessional Care, Supplement 1, May, 1-4.

Kirk, J. and M.L. Miller. (1986). Reliability and Validity in Qualitative Research. Beverly Hills, CA: Sage Publications.

Kleinbaum, A.M., T.E. Stuart, and M.L. Tushman. (2008). Communication (and Coordination?) in a Modern, Complex Organization. Working Paper Number 09-004, July. http://hbswk.hbs.edu/item/5991.html, accessed on February 20, 2014.

Lencioni, P. (2006). Silos, Politics and Turf Wars, San Francisco, CA: Jossey-Bass.

Margalit, R., S. Thompson, C. Visovsky, J. Geske, D. Collier, T. Birk, and P. Paulman. (2009). From Professional Silos to Interprofessional Education: Campuswide Focus on Quality of Care. Quality Management in Health Care, 18, (3), 165-173.

Miller, L.C., B.B. Jones, R.S. Graves, and M.C. Sievert. (2010). Merging Silos: Collaborating for Information Literacy. Journal of Continuing Education in Nursing, 41, (6), 267-272.

National Institutes of Health. (2012). Overweight and Obesity Statistics. NIH Publication 04-4158. Bethesda, MD: Weight Control Information Network.

Neebe, A.W. (1987). An Improved Multiplier Adjustment Procedure for the Segregated Storage Problem. Journal of the Operational Research Society, 38, (9), September, 815-825.

Newhouse, R.P. and B. Spring. (2010). Interdisciplinary Evidence-based Practice: Moving from Silos to Synergy. Nursing Outlook, 58, (6), 309-317.

Rogers, E.M. (2003). Diffusion of Innovations. $5^{\text {th }}$ ed. New York: Free Press.

Serrat, O. (2010). Bridging Organizational Silos. Washington, DC: Asian Development Bank, 1-5.

Shirey, M.R. (2006). On Intrapreneurship: From Silos to Collaboration. Clinical Nurse Specialist, 20, (5), 229-232.

Thomas, J.A. and G. Hern. (2006). The Organization and Architecture of Innovation: Managing the Flow of Technology. Burlington, MA: Elsever.

Vermeulen, F., P. Puranam, and R. Gulati. (2010). Change for Change's Sake. Harvard Business Review, June, 71-76.

Zorich, D.M., G. Waibel, R. Erway. (2008). Beyond the Silos of the LAMs: Collaboration Among Libraries, Archives and Museums. Dublin, OH: OCLC Research. Published online at: http://www.oclc.org/research/publications/library/2008/2008-05.pd 